\title{
MULHERES INVISÍVEIS. PRINCÍPIOS PARA UMA RECONSTRUÇÃO DO DISCURSO EM ARQUITETURA
}

\author{
INVISIBLE WOMEN. PRINCIPLES TO A RECONSTRUCTION OF THE \\ ARCHITECTURAL DISCOURSE
}

Dossiê

\section{Resumo:}

O discurso arquitetônico sempre promoveu a figura masculina enquanto ator principal. Em Portugal realidade arrastou-se até meados do século $X X$, momento em que se diplomam as primeiras arquitetas. Ainda que as circunstâncias comecem a transformar-se, tornando-se a arquitetura uma profissão que caminha para a paridade de géneros, os percursos destas arquitetas pioneiras, que quebraram preconceitos, continuam afastados do protagonismo autoral. As implicações desta lacuna no conhecimento da disciplina e da profissão torna-se evidente quando, atendendo às novas preocupações da disciplina, a revisão da história e dos seus protagonistas se torna cada vez mais pertinente, com potencialidades reveladoras de um novo modo de olhar para a profissão, de uma nova realidade.

Palavras-chave: Mulher, arquitetura, discurso

\begin{abstract}
The discourse has promoted the male figure as the main actor in the field of Architecture. In Portugal this reality was kept until the mid-twentieth century, moment when first women architects have graduated. Although the circumstances begin to change, becoming the architecture a profession that tends for gender parity, the paths of these pioneering architects, who broke prejudices are still far from the authorial protagonism. The implications of this transformation can become even more evident when, considering the new concerns of the discipline, the revision of history and its protagonists becomes increasingly relevant, with revealing potentials to a new perspective over the profession, of a new reality.
\end{abstract}

Keywords: Woman, architecture, discourse 
O discurso em Arquitetura tem construído um universo privilegiado, quer pela necessidade de síntese de uma realidade plural e complexa, quer ainda pela necessidade de afirmação na criação de um conhecimento que se apresente como verdade categórica. É evidente que o necessário processo de síntese e clarificação se traduz também na complementarização de alguns dos construtores e participantes da sua realidade, que começando por ficar numa posição complementar, rapidamente ficam para trás e são esquecidos.

A mulher como agente minoritário na maioria das áreas profissionais tem demorado a ser reconhecida, começando aqui grande parte da controvérsia que dominam os estudos de género. Perceber porque não estão as mulheres mais presentes no discurso arquitetônico poderá requerer um olhar atento, não só para o interior da profissão, mas ainda para questões de ordem social e cultural, de ordem econômico-financeira, e até de ordem pessoal.

Beatriz Colomina constitui uma autora incontornável na sua procura de sugerir novas formas de discutir Arquitetura e História, evidenciando novas ferramentas e técnicas que temos à nossa disposição para reavaliar as relações na disciplina. Ao questionar o termo normativo, defendendo a possibilidade de diferentes interpretações de um mesmo objeto e a validade de cada uma delas, a sua escrita deixa a ideia de que objetos, histórias, pessoas e instituições são autónomas e podem ser continuamente questionadas.

Nesta perspectiva, compreendemos na Arquitetura uma interdisciplinaridade que se por um lado procura construir um universo próprio, onde linguagens e modelos são únicos no seu campo de criação, por outro lado, abrange várias áreas tão opostas como das tecnologias às ciências humanas e sociais; das belas artes à gestão financeira dos orçamentos e estudos de mercado. Assim, também aos seus profissionais é incutido uma atitude esquizofrénica entre o trabalho introspetivo de atelier, à exposição pública dos seus projetos; da criação artística à resposta a expectativas de clientes alheios ao processo de projeto.

Conscientes da singularidade da atividade do arquiteto, abordamos neste artigo a entrada das mulheres na profissão em Portugal, analisando a sua experiência e modos de atuação.

Se o século XX estabeleceu uma forte alteração do modo como o sujeito mulher é visto em sociedade, numa redefinição do seu estatuto, a verdade é que no caso português encontramos, durante as principais décadas deste século, um país mergulhado num regime político de ditadura (de 1933 a 1974), cuja mentalidade paternalista atribuía à mulher um papel secundário de cuidado do lar e da família.

A exaltação de uma atitude modesta e prestadora da mulher na família e na sociedade mantiveram em Portugal o universo feminino afastado dos órgãos de decisão e poder. Ainda assim, torna-se particularmente curioso que seja exatamente nesta época que as primeiras mulheres se formam em Arquitetura, introduzindo a categoria de género na já complexa transdisciplinaridade que a Arquitetura constitui.

Se a construção da historiografia da Arquitetura se tem estabelecido numa configuração exclusivamente masculina, a feminização da profissão é uma realidade uma vez que apresenta 
atualmente uma proximidade crescente da paridade, sendo que o género masculino representa $57,9 \%$ dos profissionais portugueses ${ }^{1}$.

No entanto importa tomar em consideração duas vertentes possíveis: por um lado um possível processo de "feminização" da Arquitetura, assumindo que a entrada das mulheres no setor viria provocar alterações no modo como a atividade é exercida, ou pelo contrário, uma permanência da atitude anterior que apenas repete processos já utilizados, ou seja, os masculinos.

Se uma vertente pode indicar a diferença enquanto sinónimo de um maior enriquecimento da profissão, a outra usa a camuflagem masculina na criação de um ser único o que poderia permitir a construção de uma cultura arquitetónica universal. Deste modo McLeod alerta para os perigos da questão da individualização da mulher afirmando:

Whereas modernism's universal subject excluded women, poststructuralism's celebration of "otherness" presents another problem: Too often it consigns women to being means of constructing the identities of men. (WHITE 2001, 153).

Sobre outra perspetiva da questão, para Beatriz Colomina, o repensamento do papel do feminino provocou a reformulação da relação entre interior e exterior, afirmando que a Arquitetura viria a refletir esta transformação. Analisando a obra de dois arquitetos reconhecidos do início do século, Colomina defende que para Adolf Loos a casa não procura assumir um carácter de obra de arte, mas constitui um palco da vida familiar, num sentido mais pragmático em que cada espaço se vai adaptando consoante a sua função. Já em Le Corbusier existe a posição oposta. Numa relação aberta ao novo mundo dos meios de comunicação, a sua arquitetura não pretende ser um refúgio do exterior, mas torna-se um espaço de percepção desse espetáculo (COLOMINA 1994, 250).

Colomina apresenta uma releitura inaugural do Movimento Moderno fora da sua moldura purista/eclética, argumentando mesmo que esta tem de ser vista enquanto Mass Media, e que as questões de género quando colocadas no campo do discurso da Arquitetura tornam-se igualmente complexas e até contraditórias. Assim, quando analisamos as questões de género, em especial o género feminino, nestes discursos teremos necessariamente de abordar outras questões, perspectivar discursos complementares que nos permitam re-introduzir realidades que foram deixadas fora do mainstream cultural.

Consideramos por isso pertinente a abordagem de casos que continuam quase desconhecidos mesmo dentro do universo profissional dos arquitetos portugueses, revelando-se assim a permanência de uma valorização desigual pelo género dos atores, traduzindo-se numa invisibilidade, e com ela, um reconhecimento e valorização diminuído. A conjugação de fatores ligados a uma sociedade de construção masculina e patriarcal, mas ainda a criação de discursos

\footnotetext{
${ }^{1}$ Segundo um estudo elaborado em 2013 pela Ordem dos Arquitetos Portugueses.
} 
que privilegiaram uma linguagem dominante em detrimento da pluralidade de formas, terá dado origem a um conhecimento proveniente de uma segregação de realidades secundárias.

Assim, para além da desigualdade de género, em Arquitetura, torna-se urgente analisar as áreas e modos de atuação na profissão. Verificamos que ao longo de séculos o arquiteto tornou-se um profissional habilitado a conceber desde as maiores escalas de planeamento de território, às micro escalas de desenho de pormenor de objetos.

Este modelo "aberto" de profissão, se por um lado a configura com uma flexibilidade interessante, por outro lado torna-se difícil de definir e de estabelecer uma percepção clara dos seus limites. Deste modo o discurso em arquitetura procurou assegurar uma unidade da sua obra criando uma aura elevada que supera a sua capacidade técnica ou profissional, remetendo estas figuras para lugares de estrelato, ou de "mestres autores".

No caso português, a entrada feminina nas Escolas de Arquitetura deu-se de forma quase natural, visto que o curso era lecionado nas Escolas de Belas Artes, partilhando espaço e algumas disciplinas com os cursos de Pintura e Escultora (onde as mulheres já ocupavam uma posição reconhecida). No entanto, torna-se claro que a sua aceitação por parte dos professores e colegas não era tão pacífica.

As arquitetas relatam que a sua condição feminina era constantemente lembrada, especialmente quando se pretendia estabelecer as "desejadas" características (masculinas) da disciplina e da profissão, fazendo dos elementos do gênero feminino atores complementares da obra arquitetônica. Às mulheres era relembrada a condição de donas de casa, "a coser meias", admitindo-se mesmo que a criação de um estatuto profissional após a formação académica seria bastante dificultado ${ }^{2}$.

Se o reconhecimento no meio escolar não foi fácil nem imediato, o mundo profissional estava ainda menos preparado para receber estas mulheres uma vez que a própria classe profissional dos arquitetos custava a afirmar-se numa sociedade onde os engenheiros desde cedo ocupavam uma posição de destaque no sector da construção. A ligação destes últimos ao poder político permitia-Ihes por um lado receber as grandes encomendas estatais, ao mesmo tempo que a propaganda estatal, com as grandes obras de representação transmitia à sociedade essa imagem preponderante do engenheiro enquanto técnico habilitado.

A própria indefinição dos arquitetos, na sua dualidade entre as Belas Artes e a Técnica, mas também o seu fraco poder de representação. Quando em 1933 engenheiros, médicos e advogados regulamentavam as suas Ordens Profissionais, os arquitetos demorariam até $1998^{3}$ para o fazer, sendo um dos fatores do processo moroso no reconhecimento da profissão em

\footnotetext{
${ }^{2}$ A arquiteta Antonieta Jacinto relata que quando se dirigiu à Escola de Belas Artes de Lisboa foi só após muita insistência que Ihe foi permitido inscrever-se no curso de Arquitetura, pois segundo o funcionário da secretaria:" o senhor diretor (Luís Cunha) não gostava de meninas". Declarações de Antonieta Jacinto em entrevista a 27 de Agosto de 2014 à autora deste artigo.

${ }^{3} \mathrm{Em} 1933$ os arquitetos portugueses organizam-se num Sindicato, posteriormente em 1978 formam uma Associação e apenas em 1998 constituem a Ordem dos Arquitetos Portugueses.

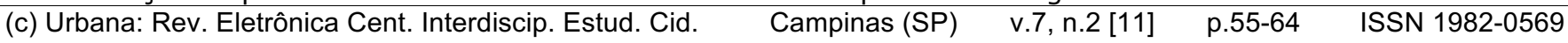


Portugal. Assim, a profissionalização feminina em arquitetura foi ainda mais tardia do que em engenharia civil, concordando com a falta de reconhecimento e afirmação da profissão.

As primeiras arquitetas confrontar-se-iam com dificuldades acrescidas na sua entrada no meio, pois para além de representarem uma ruptura com a normalização masculina da disciplina praticada e divulgada até aí, encontravam-se ainda numa posição delicada perante uma sociedade que não reconhecia o valor do trabalho do arquiteto, e ainda menos de uma mulher arquiteta. A primeira arquiteta portuguesa, Maria José Brito Estanco tornar-se-ia um exemplo flagrante disto mesmo, não conseguindo trabalho enquanto arquiteta e sendo mesmo caricaturada nos jornais na época (PEDROSA 2010) que não acreditavam que uma mulher tivesse capacidades para o trabalho na construção.

Quando o discurso oficial defendia que o lugar da mulher era o lar, no seu cuidado e da manutenção da família; ser profissional, ainda mais numa área como a arquitetura, exigia uma atitude e determinação excecionais ${ }^{4}$ (CARREIRO 2013). A primeira geração de arquitetas, formadas na década de 40 constituem um pequeno grupo de cinco mulheres, das quais se conhece principalmente o caso de Maria José Marques da Silva, pela sua relação familiar e profissional ao atelier Marques da Silva.

Torna-se particularmente interessante a percepção de que em Arquitetura a entrada na profissão se fez como vários séculos antes se fizera nas Artes. Como refere Neide Jallageas

entre meados do ano de 1500 até o século XIX, várias artistas conseguiram desenvolver significativos trabalhos de criação. Normalmente eram filhas de artistas de sucesso e trabalhavam no próprio atelier do pai" (JALLAGEAS 2000, $6)$.

Assim, se à primeira geração de arquitetas o acesso a uma carreira foi dificultado, tornando-se essencial a intercessão de outros (como foi o caso de Maria José Marques da Silva ${ }^{5}$ ), para as arquitetas diplomadas na década seguinte(anos 50) as condições tornar-se-iam mais favoráveis. Uma maior divulgação do curso entre os pares femininos levaria a um aumento do número de diplomadas para 12 (cinco no Porto e sete em Lisboa), constituindo esta a real época de abertura da disciplina ao sector feminino. As arquitetas desta década de 50 ingressaram nos ateliers enquanto colaboradoras, entraram nos serviços públicos, abriram atelier em nome próprio e desenvolveram carreiras profissionais relevantes.

Maria Emília Guedes Castro surge como um exemplo paradigmático no Porto. De forma determinada e audaz, ainda na década de 50 inaugura um atelier próprio, dedicando-se à

\footnotetext{
${ }^{4}$ Segundo María Carreiro: "Las pioneras, aquellas que decidieron elegir unos estudios y una profesión tan exigentes, rompen estereotipos; han mostrado ser poseedoras de una personalidad fuerte, decidida, de una gran inteligencia y capacidad".

${ }^{5}$ Maria José Marques da Silva foi uma das primeiras mulheres a obter o diploma de arquiteta. Ao contrário de Maria José Estanco que não tinha contatos dentro da profissão, a primeira era filha do afamado arquiteto do Porto, José Marques da Silva e casada como o arquiteto David Moreira da Silva.
} 
profissão em regime liberal. Se o facto de ser mulher a trabalhar sozinha numa profissão masculina era certamente à época pouco usual, foi a paixão pela profissão a principal motivação para o esforço acrescido que esta condição exigia.

Apesar da falta de reconhecimento conferido a estas profissionais, atendendo às experiências anteriores de mulheres arquitetas, esta profissional destaca-se pela sua determinação, empenhando-se a aplicar os conhecimentos que adquirira na sua formação e aceitando todos os trabalhos que Ihe eram solicitados. Ao contrário de uma perspetiva elitista da arquitetura, Maria Guedes Castro acreditava que a profissão se fazia desde a grande escala dos equipamentos hospitalares até à pequena escala do desenho de interiores, sem que a variabilidade entre estas duas escalas diminuísse o valor do profissional ou da sua ação.

Porém o discurso de mainstream geralmente privilegia, tal como sempre privilegiou, as grandes obras que constroem algo excecional, de um protagonismo declarado e cuja assinatura do arquiteto envolvido possa ficar bem presente. Maria Guedes Castro mostra-nos com a sua experiência um modelo diferente. Cada obra, cada projeto era encarado como uma forma de melhorar a realidade existente, reiterando isto pelo facto de vários colegas de profissão se admirarem com o volume de trabalhos que aceitava, que na verdade eram em grande parte pequenas obras que muitos arquitetos recusavam por não considerarem suficientemente aliciantes.

Estas mesmas características permitiram-Ihe construir a sua carreira através de trabalhos onde a proximidade com os intervenientes na obra era constante e a dedicação a cada projeto levava a um cuidado minucioso relativamente a cada escala de projeto.

Ainda assim, o facto de trabalhar em obras com menos exposição pública ou de menor notoriedade não significa que não exigisse a valorização do seu trabalho, nunca aceitando a condição de invisibilidade do trabalho enquanto colaboradora de um atelier. Tomamos então consciência de que a arquitetura tem sido construída em grande parte sob a aura da obra artística que se recusa a descer a uma escala menor como que se o seu envolvimento na esfera comum determine a perca da sua dignidade. Este outro lado, muitas vezes menosprezado, não narrado pelos grandes volumes da História, não difundido nos museus, representa porém, numa escala real, a verdadeira essência da disciplina: adaptada às necessidades e que molda os conhecimentos de séculos de técnica e estética a favor da sociedade.

Importa então referir que, se existiram profissionais como Maria Castro que fizeram questão de demarcar-se e exercer a profissão, outras, pelo facto de não serem reconhecidas como iguais competidoras, acabariam por desistir e permanecer ora na sombra de uma figura masculina, ou simplesmente desistir da profissão, ingressando (muitas delas) no ensino liceal.

Existe ainda algumas outras possibilidades. Considerando as variantes possíveis dentro da profissão, muitas viriam a trabalhar em funções do Estado, ingressando nos diversos Serviços de Construções Públicas, sem se sentirem especialmente motivadas a ter uma posição de protagonismo autoral.

Arícia Ferreira, arquiteta diplomada durante a década de 50 na Escola de Belas Artes de Lisboa desenvolveu parte da sua carreira em projetos em colaboração com o seu marido (c) Urbana: Rev. Eletrônica Cent. Interdiscip. Estud. Cid. $\quad$ Campinas (SP) $\quad$ v.7, n.2 [11] $\quad$ p.55-64 ISSN 1982-0569 
(também arquiteto) e enquanto colaboradora de um atelier. Porém a sua principal atividade viria a ser para o Estado português nas construções da Previdência. Nesta função, conta que a dado momento da sua carreira foi convidada para ascender a um cargo de topo, porém recusou o mesmo uma vez que não se revia naquele modelo, preferindo manter a posição anterior. Neste sentido também a autora Maria Cristina Bombelli nos alerta que as motivações pessoais são aspetos fundamentais na criação de uma carreira (BOMBELLI 2011,48).

Claro que, por outro lado, quando atualmente vemos grandes figuras femininas que se afirmam e produzem percursos brilhantes damo-nos conta de que é também resultado de uma sociedade que tem vindo a assemelhar os géneros, destacando-se a individualidade de cada um e não tanto por categorias biológicas que em grande parte deixaram de ser determinantes. Porém esta ideia de pico de evolução contemporânea é beliscada quando, apesar das notórias conquistas no feminino em diversos domínios, é ainda incontornável uma clara desigualdade entre géneros, principalmente quando entram em jogo questões econômico-financeiras, mas ainda socioculturais cujas raízes são difíceis de eliminar.

Deste modo torna-se determinante, ao analisar as questões de género, procurar determinar as razões para a invisibilidade ou subvalorização de uma parte em detrimento de outra, pois se é evidente que a sociedade foi construída sob um modelo machista e patriarcal, também é muitas vezes verdade que o grupo feminino promoveu muitas vezes a sua própria desvalorização ao abdicar de determinadas funções e posições que the permitiriam ter um reconhecimento diferenciado (STRATIGAKOS 2013, 2) ${ }^{6}$.

Porém é ainda necessário olhar para as diversas vertentes do discurso arquitetônico, pois se até ao momento falamos dos criadores e promotores do discurso de mainstream, teremos ainda de analisar o papel dos seus atores. Assim, se por um lado constatamos que os grandes mestres constituíram personagens alicerçadas em auras de singularidade e genialidade, foram muitas vezes os próprios que promoveram essa imagem e contribuíram para ela. Neste sentido, Beatriz Colomina defende a importância da "autopromoção" que Le Corbusier soube desenvolver. Para além das suas qualidades enquanto arquiteto, refere mesmo que o facto de hoje, em pleno século XXI, a sua figura continuar presente no imaginário da arquitetura como grande referência de deve à capacidade que Le Corbusier teve na integração das novas ferramentas visuais para divulgar as suas ideia e conceitos, capaz de influenciar a própria imagem da obra construída e construindo um discurso singular?

A construção de narrativas geniais está presente nos percursos de muitos outros grandes arquitetos, ao mesmo que foram construindo carreiras notáveis, deixando as suas marcas e assinaturas. Teremos então de considerar que não sendo possível trabalhar

\footnotetext{
6 Admittedly, women have sometimes contributed to their own disappearance. Male architects do not hesitate to take an active role in preserving their legacies by writing memoirs and ensuring the safe-keeping of their models, drawings and correspondence. Women - taught that self-promotion is an unattractive female trait - have made less effort to tell their stories.
}

${ }^{7}$ Colomina, Beatriz, Privacy and Publicity, Modern Architecture as mass media, p. 220 
isoladamente em arquitetura, certamente muitos foram os colaboradores que ficaram apagados na sombra do grande foco que emanava sobre estes afamados "mestres".

Neste sentido as mulheres formam uma parte deste grupo uma vez que na sua grande maioria não desenvolveram carreiras individuais, nem sequer conseguiram ou quiseram destacar-se isoladamente enquanto autoras. Teremos ainda de analisar que, pelo contrário, são as próprias mulheres que muitas vezes não fazem um esforço por divulgar o seu próprio trabalho e, claro, ainda que inconscientemente reservam-no para um lado complementar e até esquecido.

Considerando que atualmente tem havido uma procura de resgatar alguns destes nomes da penumbra, beneficiaremos então da oportunidade de analisar os casos nos quais as mesmas foram impedidas desse tipo de notoriedade do discurso ou, por outro lado, quando elas próprias se alhearam à criação e desenvolvimento do mesmo.

Se é evidente a crescente procura das arquitetas esquecidas que trabalharam com grandes arquitetos do século XX, o caso português ainda continua inexplorado. Desta forma, casos como Jane Drew, Denise Scott Brown, Margareth Schutz Lihotzky, que trabalharam respetivamente com Le Corbusier, Robert Venturi e Mies van der Rohe, tomando hoje uma relevância e interesse crescente pela desmitificação das formas de construção do discurso arquitetônico e pela exploração de discursos alternativos, demonstram ao mesmo tempo as potencialidades de um alargamento para outros territórios.

Deste modo, no caso português poderemos tratar casos de arquitetas como Maria Natália Gomes que trabalhou com Manuel Vicente; Maria Noémia Coutinho que trabalhou com José Carlos Loureiro; ou Antonieta Jacinto que trabalhou com Francisco Silva Dias, revelando que a obra arquitetônica é na verdade produto de criações partilhadas, de construção colaborativa e cuja magnificência não surgiu de um momento de inspiração genial individualista, mas de uma ação conjunta de reconhecimento das necessidades e potencialidades de um projeto. Consideramos, portanto que um dos principais motivos pelo qual se deve estudar a presença das mulheres será mostrar a realidade da profissão nas suas diferentes variantes e dinâmicas, pois se a profissão for só construída por grandes mestres o que é que isso diz dela? (LANGE, 2013).

Olhando a questão nesta perspectiva torna-se ainda relevante pensar na forma como a História tem sido construída e a responsabilidade dos investigadores que a têm nessa mesma construção do conhecimento. A invisibilidade das questões femininas são, por certo, também resultado de um foco em outras questões. Como afirmou Mae Barbosa:

Ignorância sobre a Arte das mulheres como reclamam Griselda Pollock, desde muito tempo, e, mais recentemente, Frances Spalding não significa apenas esquecimento de seus nomes, destruição de suas obras pelo descaso mas principalmente "invisibilidade de significação" (JALLAGEAS 2000, 3).

Assim, é neste ponto que a crescente preocupação e denúncia da complementaridade que o grupo feminino ocupa se torna pertinente pois demonstra não só a prevalência de um 
discurso diferente, mas ainda uma forma de não valorização ou até mesmo de exclusão e apagamento de um segmento do conhecimento, dos seus autores, colocando em causa o seu reconhecimento e, com isto, a consciência da sua existência em tempos futuros.

A complementaridade do discurso feminino, mas também a escassa divulgação que é feita do mesmo constitui portanto uma forma de exclusão e de menosprezo de determinadas vertentes da nossa cultura. Deste modo torna-se cada vez mais aliciante tomar em consideração questões que ao logo dos tempos têm sido negligenciadas ou, como María Carreiro afirma: "muchos de los temas que se investigan o se abordan nacen de las reflexiones marginales que surgen al tratar otras cuestiones"(CARREIRO 2013).

Assim, abordar o discurso arquitetónico, interrogando os seus métodos e modos de construção constitui então, em si mesmo, uma nova atitude a adotar na definição do objeto de estudo. Como afirmou Dubois citado por Neide Jallageas:

Entrar pela grande porta central, prevista para tanto, e em que tudo já fica organizado para ser visto de frente, parece-me menos agudo, menos pertinente, menos instigante, do que imiscuir-se pelo lado, por uma pequena entrada lateral que permitirá ver coisas inéditas (nunca vistas desta maneira) (JALLAGEAS 2000).

Em suma, verificamos que hoje a sociedade procura reformular valores como a identidade e a individualidade, ao mesmo tempo que se insurge contra modelos de discursos acéticos de um academismo puro, frequentemente encarados como uma forma de ostentação. A crítica fica então numa posição desconfortável entre o desejo de autoridade conceptual da Arquitetura e a adaptação a morfologias mais livres e próximas do individuo comum.

Podemos então concluir que, a crítica em Arquitetura encontra-se hoje em processo de reformulação, moldada pela indefinição da época contemporânea. Em particular no campo da Arquitetura, acreditamos que a crescente feminização do sector poderá dar pistas para uma alteração do seu discurso, mas ainda de forma mais abrangente, das formas de construção da disciplina, dos seus modos de intervenção e interação na realidade.

Revela-se então necessário ver a questão através de óticas diversas, refletindo nos significados e relações possíveis de estabelecer para uma percepção profunda da questão. Neste processo é por isso fundamental renovar a Academia, enquanto incubadora dos novos profissionais, das inovações a introduzir e das potencialidades futuras. Se certamente a legislação poderá tornar-se mais inclusiva nas relações entre género e cultura, é na aproximação da arquitetura à política e à sociedade que parece fundamental analisar não só os fatores da marginalização do discurso feminino, mas ainda as formas de replicação da mesma.

Deste modo será criada a oportunidade de redefinição do discurso arquitetônico, ampliando a diversidade dos modelos divulgados, nas suas formas e origens, numa distribuição igualitária do poder político, económico e social, refletindo-se na sustentabilidade do desenvolvimento e promovendo estratégias de recuperação de imagens antes invisíveis. 


\section{Referências}

BENJAMIN, Walter. 2010. O Anjo da História. Trad. Barrento. Lisboa: Assírio \& Alvim.

BISMARCK, Pedro. A promessa da Arquitectura. Considerações sobre a geração por vir. Consultado a 10 de Dezembro de 2015. Disponível em: http://artecapital.net/arq des-87-apromessa-da-arquitectura-consideracoes-sobre-a-geracao-por-vir. Acesso em: 08 de Set de 2012

BOMBELLI, Maria Cristina. 2011. Alice no país dos negócios. Como tornar-se uma líder permanecendo mulher. Lisboa: Babel.

BRANDÃO, Pedro. 2006. O Arquiteto e Outras imperfeições: ética, identidade e prospetiva da profissão. Lisboa: Livros Horizonte.

BRUNO, Cristina. (maio de 2007). Museus e Patrimônio Universal. In V Encontro do ICOM BRASIL, Fórum dos Museus de Pernambuco. Recife.

CARREIRO, Maria. (2013). Mujeres Arquitectas de Galicia. Disponível em www.galarq.com/entrevista-a-maria-carreiro-mulleres-arquitectas-de-galicia-maga. Acesso em 27 Dez 2013

COLOMINA, Beatriz (ed.) 1992. Sexuality \& Space. New Jersey: Princeton Architectural Press.

COLOMINA, Beatriz. 1994. Privacy and Publicity. Modern Architecture as Mass Media. Massachusetts: The MIT Press.

DUBY, Georges e Perrot, Michelle. 1994- 1995. História das mulheres no ocidente. Vols. 1 5. Trad. Maria Helena da Cruz Coelho, Irene Maria Vaquinhas, Leontina Ventura e Guilhermina Mota. T. Orig. "Storia delle donne". Porto: Afrontamento.

FOUCAULT, Michel. 1966, As palavras e as coisas. Lisboa: Edições 70

JALLAGEAS, Neide. Respostas mínimas a questões máximas: sobre a (in)visibilidade da mulher artista na história da arte. [online], 2000. Disponível em http://www.academia.edu/8129168/Respostas_m\%C3\%ADnimas_a_quest\%C3\%B5es_m\%C3 \%A1ximas sobre a in visibilidade da mulher artista na hist\%C3\%B3ria da arte. Acesso em:_16 Out 2014 